\title{
Estimation of the ground shaking from the response of rigid bodies
}

\author{
FILOMENA DE SILVA ${ }^{1}$, STEFANIA SICA ${ }^{2}$, FRANCESCO SILVESTRI ${ }^{3}$, \\ STEFANO AVERSA 4 \\ 1 Department of Civil, Architectural and Environmental Engineering, Uni- \\ versity of Napoli Federico II, Napoli, Italy; filomena.desilva@unina.it; \\ 2 Department of Engineering, University of Sannio, Benevento, Italy \\ 3 Department of Civil, Architectural and Environmental Engineering, Uni- \\ versity of Napoli Federico II, Napoli, Italy \\ 4 Department of Engineering, University of Napoli Parthenope, Napoli, Italy
}

\begin{abstract}
The paper illustrates and compares simplified approaches to interpret the mechanisms of damage observed on rigid bodies in the cemetery of Amatrice, after the first strong-motion event (August 24, 2016, $\left.M_{W}=6.0\right)$ of the seismic sequence occurred in Central Italy. The final goal of the work is to link the observed movements of the fallen objects to specific characteristics of the ground motion recorded on site.
\end{abstract}

\section{INTRODUCTION}

$\Lambda$ fter a strong earthquake, information on ground motion characteristics can be indirectly derived from the observation of the damage suffered by objects with quite simple geometry and known degrees of freedom, for which the collapse mechanism is straightforward and simple to back-figure. This methodology, borrowed from the archeoseismology, takes into account not only the inventory and amount of the occurred damage, but also the failure mechanisms and the pattern of displacement of the fallen objects. The back-analysis of these latter aspects may provide useful information on the amplitude of ground motion parameters (if no seismic stations are available nearby) or on other aspects of the seismic shaking (directivity, impulsive motion, etc.). Previous works on such an issue may be found in Yegian et al. (1994), Athanasopoulos (1995) and Lanzo et al. (2010). Conversely to inhabited areas, most of the injured cemeteries are not closed soon after a strong earthquake or - if seriously damaged - they may be inspected in a second stage, before any reconstruction or restoration. The above mentioned literature showed that their inspection soon after the main shock, or even later, may be very useful to have additional insight into the ground motion occurred on site.

During the GEER reconnaissance operations (Stewart et al., 2016) after the $M_{W} 6.0$ first strong motion event (August 24, 2016, local time 3.32 a.m.) of the seismic sequence in Central Italy, many interesting cases of fallen gravestones, funerary monuments and statues were observed in the cemetery of Amatrice 
(Figures 1a). This is located about $400 \mathrm{~m}$ SouthEast and at approximately the same elevation of the main gate of the historical center (Figure 1a), which suffered a local $\mathrm{I}_{\mathrm{MCS}}=10.5$ (Galli et al., 2016). All the objects apparently fell down during the first event, and most of them along the NS direction (Figures 1b-e).
Among the rigid objects showing regular geometry and clear damage pattern, an obelisk was selected in order to develop a simple analysis to relate the observed failure mechanism to the ground motion occurred at the site. (a)

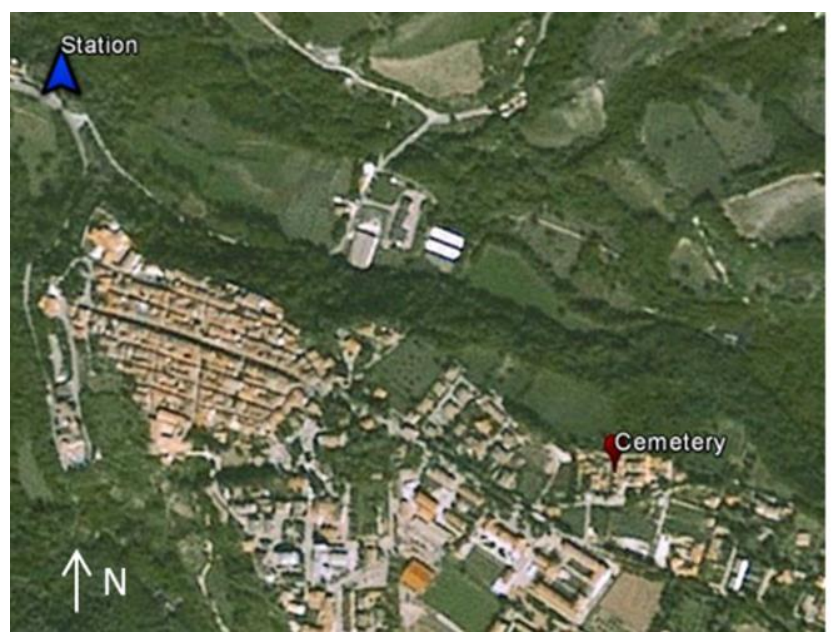

(c)

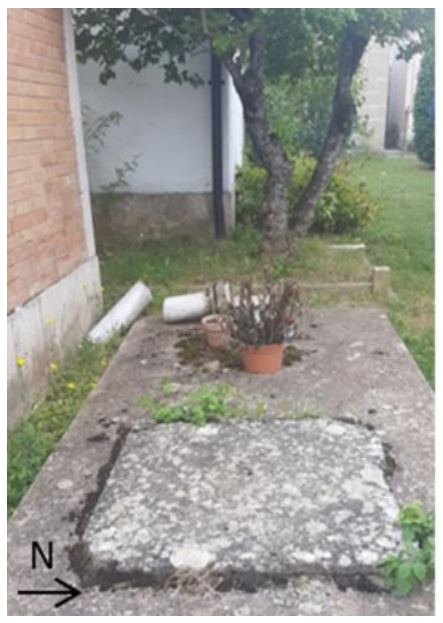

(d)

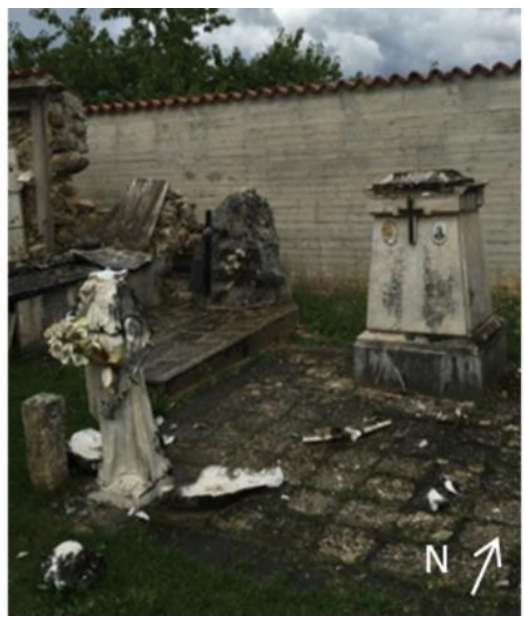

(b)

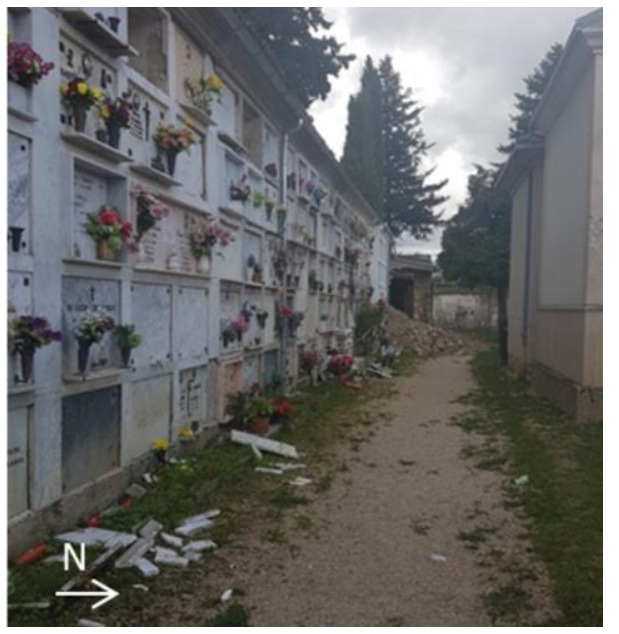

(e)

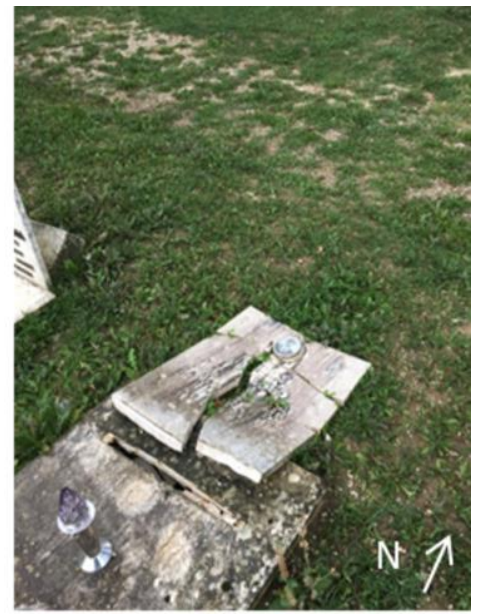

Figure 1. Location of the cemetery and of the seismic station at Amatrice (a), damages to statues, monuments and graves in the Amatrice cemetery (b-e). 


\section{THE CASE STUDY OF THE MARBLE OBELISK}

The selected case study concerns the failure of the marble obelisk shown in Figure 2. The obelisk has a shape of a truncated pyramid and it is approximately $1.10 \mathrm{~m}$ high. The width of the square cross section tapers with the height from $0.27 \mathrm{~m}$ at the base up to $0.13 \mathrm{~m}$ at the top. The base section was attached through a thin layer of mortar to a stone basement, about $0.80 \mathrm{~m}$ high. The detected geometry and the height of the gravity center are reported in Table 1.

During the reconnaissance, the obelisk was found lying on the ground, apparently over-

(a)

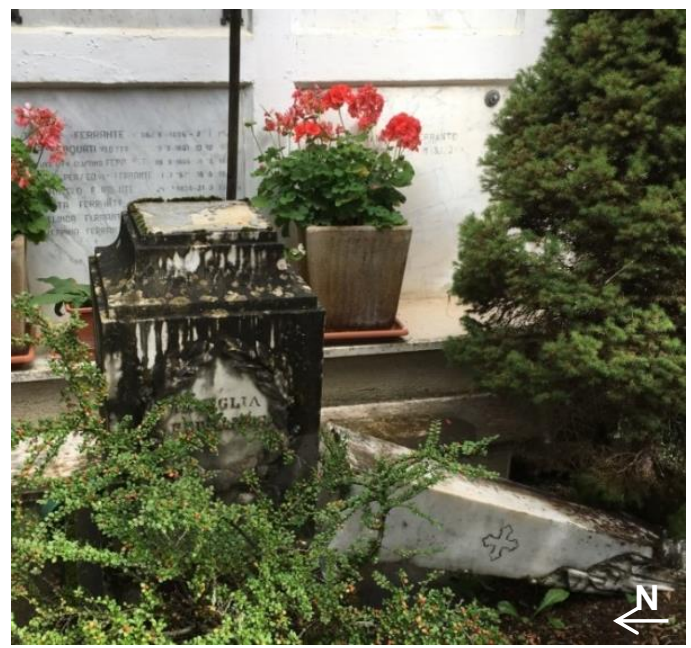

turned along the NS direction (Figure 2a), while the weak mortar connection failed (Figure $2 b$ ).

Table 1. Geometrical parameters of the obelisk.

\begin{tabular}{ccccc}
$\begin{array}{c}\text { Lower } \\
\text { width }\end{array}$ & $\begin{array}{c}\text { Upper } \\
\text { width }\end{array}$ & Height & $\begin{array}{c}\text { Gravity } \\
\text { center } \\
\text { height }\end{array}$ & $\begin{array}{c}\text { Slenderness } \\
\text { ratio }\end{array}$ \\
\hline $\mathrm{B}$ & $\mathrm{b}$ & $\mathrm{h}$ & $\mathrm{h}_{\mathrm{G}}$ & $\chi$ \\
$(\mathrm{m})$ & $(\mathrm{m})$ & $(\mathrm{m})$ & $(\mathrm{m})$ & $(/)$ \\
\hline & & & & \\
0.27 & 0.13 & 1.10 & 0.49 & 1.78 \\
\hline
\end{tabular}

(b)

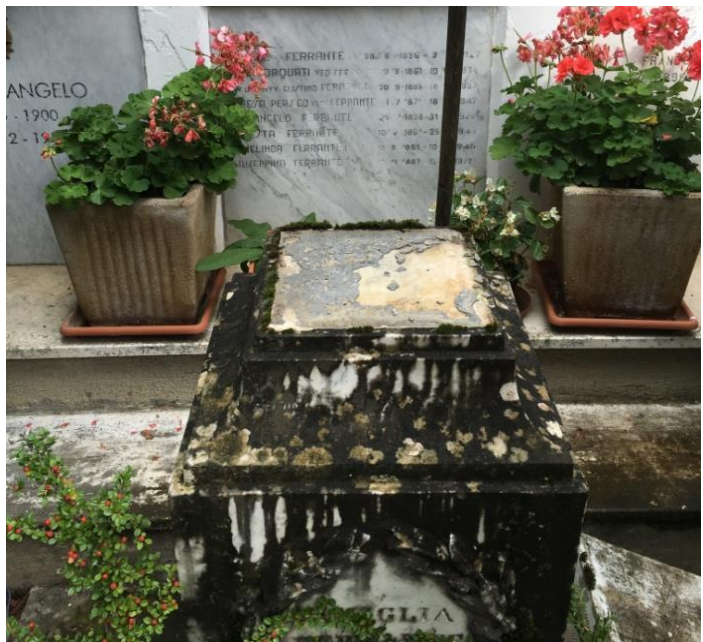

Figure 2. Damaged obelisk in the Amatrice cemetery (a), particular of the base section (b).

\section{FAILURE CONDITIONS}

Neglecting the vertical component of the seismic acceleration, the forces acting on the obelisk during the earthquake (Figure 3) are its weight, $\mathrm{W}$, and a horizontal inertia force $\mathrm{H}=\mathrm{ma}$, corresponding to the seismic action on the mass, $\mathrm{m}$. Due to the high stiffness of the marble, both the basement and the obelisk behave as rigid bodies: thus, the horizontal acceleration of the obelisk can be considered equal to the ground acceleration, $a(t)$, at the site of the cemetery, from the beginning of the shaking until when it detached from the basement 
and failed. Since the likely failure mechanisms are brittle, it is possible to estimate a lower bound for the maximum ground acceleration from the horizontal force, $\mathrm{H}_{\mathrm{f}}$, that produces the failure of the obelisk. Being difficult to quantify the degree of the constraint exerted by the mortar layer, two limit conditions were considered:

1. the horizontal force is determined by the limit equilibrium in terms of sliding and toppling of the obelisk, assuming a purely frictional marble-mortar interface (Figure 3a);

2. the horizontal force corresponds to the achievement of the strength, in terms of compression and shear stress, in the reacting zone of the base (Figure 3b-c).

According to the first approach, the acceleration amplitudes (expressed in g) required to produce the horizontal translation and the ro-

(a)

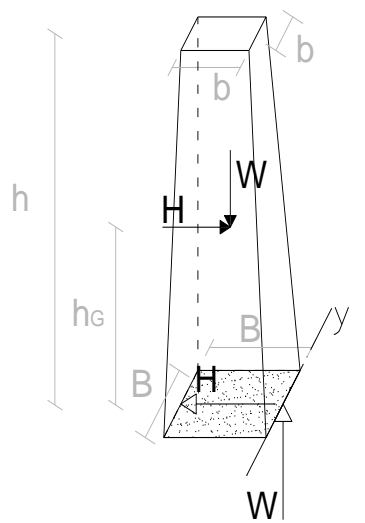

(b)

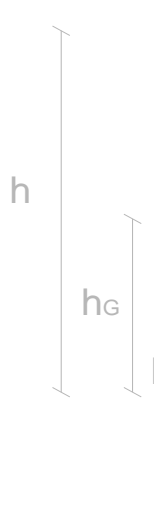

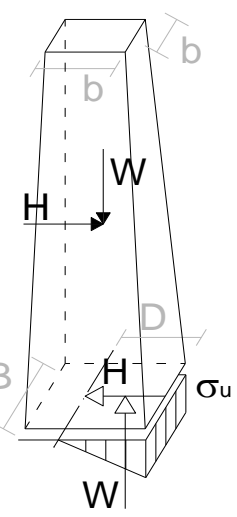

(c)

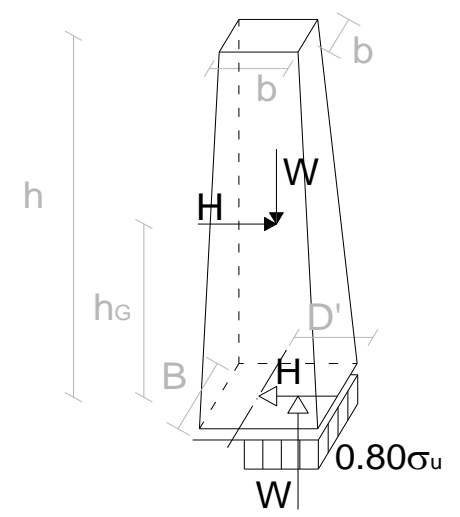

Figure 3. Approach $n^{\circ} 1$ (a) and $n^{\circ} 2$, corresponding to the onset of the yielding (b) and to the collapse (c) of the obelisk.

The first translational mechanism does not necessarily lead to a global failure: in fact, the obelisk can accumulate sliding displacements along the base recovering a final global equilibrium, according to the Newmark (1965) rigid block model. In the case at hand, the width of the basement is similar to that tation around the y axis (Figure 3a) can be respectively computed as follows:

$$
\begin{gathered}
\mathrm{a}_{\mathrm{S}}=\mu \\
\mathrm{a}_{\mathrm{M}}=\frac{1}{2 \chi}
\end{gathered}
$$

where:

- $\quad \mu$ is the friction coefficient of the marblemortar interface,

$\chi$ is the slenderness ratio of the obelisk, given by:

$$
\chi=\frac{\mathrm{h}_{\mathrm{G}}}{\mathrm{B}}
$$

of the base of the obelisk. For this reason, the accumulation of horizontal displacements can induce a sort of "second order" effect, leading to the toppling of the obelisk when the cumulated displacement overcomes half of its base width. In this way, the acceleration producing the sliding mechanism can be 
considered as a lower bound of the maximum acceleration of the basement which is required to produce global instability.

Following Maiorano et al. (2015), the onset of rotation with the second type of failure mechanism does not necessarily induce a toppling failure, since the block can recover a stable position after some bouncing on the base. Also in this case, the acceleration amplitude that triggers the first rotation can be considered as a lower bound of that required for producing failure.

The second approach is based on the hypothesis that the limit compression stress, $\sigma_{u}$, is achieved at the edge of the resisting zone of the base section, this latter assumed with a width equal to $D$. This condition corresponds to the onset of the first yielding in the mortar section. From Figure 4a, the equilibrium of the obelisk is determined by:

- vertical translation:

$$
\mathrm{W}=0.5 \sigma_{\mathrm{u}} \mathrm{DB}
$$

- rotation around the gravity center of the base section:

$$
\mathrm{ma}_{\mathrm{M}} \mathrm{h}_{\mathrm{G}}=0.5 \sigma_{\mathrm{u}} \mathrm{DB}\left(\frac{\mathrm{B}}{2}-\frac{\mathrm{D}}{3}\right)
$$

- horizontal translation:

$$
\mathrm{ma}_{\mathrm{S}}=\mathrm{cDB}+\mu \mathrm{W}
$$

In this latter equation, it is assumed that the shear strength at the interface obeys to the Mohr-Coulomb criterion. From the equilibrium under the vertical action $\mathrm{W}$ (eq. 4 ), the value of $\mathrm{D}$, corresponding to the achievement of the compression limit stress at the edge of the base section, is calculated. From eqs. (5)-(6), the acceleration amplitudes corresponding to the ultimate moment, $\mathrm{a}_{\mathrm{M}}$, and to the shear strength, $\mathrm{as}_{\mathrm{s}}$ can be respectively computed. (a)

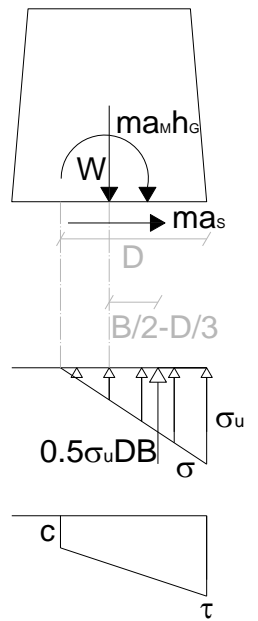

(b)

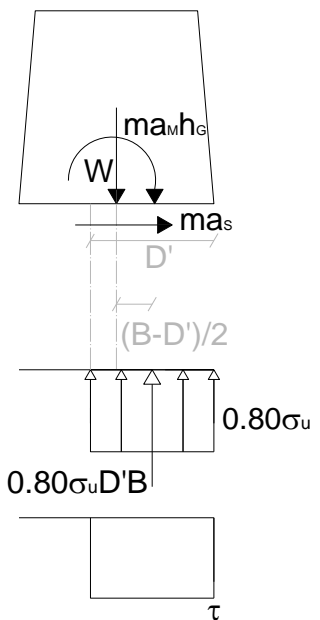

Figure 4. Equilibrium of the base section for the second approach, corresponding to the onset of the yielding (a) and to the collapse (b).

With the propagation of yielding, the full plastic failure occurs with non-linear stress distribution at the stone-mortar interface (see Figure $4 b$ ). Just like commonly assumed in concrete structures, it can be hypothesized that plastic failure corresponds to the achievement of a mean $0.80 \sigma_{u}$ in the whole resisting zone of the base section, the width of which reduces to $\mathrm{D}^{\prime}$. In this condition, the equilibrium equations become:

$$
\begin{gathered}
\mathrm{W}=0.80 \sigma_{\mathrm{u}} \mathrm{D}^{\prime} \mathrm{B} \\
\mathrm{ma}_{\mathrm{M}} \mathrm{h}_{\mathrm{G}}=0.80 \sigma_{\mathrm{u}} \mathrm{D}^{\prime} \mathrm{B}\left(\frac{\mathrm{B}-\mathrm{D}^{\prime}}{2}\right) \\
\mathrm{ma}_{\mathrm{S}}=\mathrm{cD} \mathrm{D}^{\prime} \mathrm{B}+\mu \mathrm{W}
\end{gathered}
$$




\section{RESULTS}

The two approaches illustrated in the previous section were applied to the case study of the obelisk, in order to compute two respective couples of limit accelerations, as and $\mathrm{a}_{\mathrm{M}}$. The geometrical dimensions, including the slenderness ratio are those reported in Table 1 , while the physical and mechanical parameters adopted in the calculations are summarized in Table 2.

Table 2. Parameters assumed in the calculations.

\begin{tabular}{cccccc} 
& $\begin{array}{c}\text { Unit } \\
\text { weight }\end{array}$ & Weight & $\begin{array}{c}\text { Compression } \\
\text { limit stress }\end{array}$ & \multicolumn{2}{c}{$\begin{array}{c}\text { Shear } \\
\text { strength }\end{array}$} \\
\cline { 2 - 7 } App. & $\gamma$ & $\mathrm{W}$ & $\sigma_{\mathrm{u}}$ & $\mathrm{c}$ & $\mu$ \\
& $\left(\mathrm{kN} / \mathrm{m}^{3}\right)$ & $(\mathrm{kN})$ & $(\mathrm{MPa})$ & $(\mathrm{MPa})$ & $(/)$ \\
\hline 1 & 27.00 & \multirow{2}{*}{1.30} & $/$ & $/$ & 0.40 \\
2 & & & 1.00 & 0.34 & 0.40 \\
\hline
\end{tabular}

In details:

$\mathrm{W}$ was evaluated from the geometry and the marble unit weight, $\gamma$;

the compression limit stress, $\sigma_{u}$, was assumed on the basis of the lowest class (M1) of the European classification of the mortar (EN 998:2), included in EC6 (EN 1996-1-1; 2006);

the frictional strength coefficient, $\mu$, is the typical value adopted for the mortar adopted in the masonry (EN 1996-1-1; 2006);

the cohesion, c, was back-calculated from $\sigma_{u}$ and $\mu$ through the Mohr-Coulomb criterion, adopted to model the shear strength of the marble-mortar interface.

Since the only vertical load considered is the weight of the obelisk, the limit value $\sigma_{u}$ is achieved in the section for a very low length of the resisting zone $\left(D=0.01 \mathrm{~m} ; \mathrm{D}^{\prime}=0.005 \mathrm{~m}\right)$.
As a consequence, the solutions of the equilibrium in correspondence of the first yielding and of the full plastic failure are coincident. Moreover, they are close to the results of the first approach, as synthesized in Table 3.

Table 3. Computed limit accelerations.

\begin{tabular}{cc|cc}
\multicolumn{2}{c|}{ Approach 1 } & \multicolumn{2}{c}{ Approach 2 } \\
\hline $\mathrm{a}_{\mathrm{M}}$ & $\mathrm{a}_{\mathrm{S}}$ & $\mathrm{a}_{\mathrm{M}}$ & $\mathrm{a}_{\mathrm{S}}$ \\
\hline$(\mathrm{g})$ & $(\mathrm{g})$ & $(\mathrm{g})$ & $(\mathrm{g})$ \\
0.28 & 0.40 & 0.27 & 0.40 \\
\hline
\end{tabular}

The obtained results highlight that:

- the relatively high slenderness of the obelisk makes it overturn under a seismic action lower than the value corresponding to the onset of sliding, as well as the acceleration associated to the ultimate moment at the base section results lower than that related to the ultimate shear force;

according to both approaches, the ground acceleration in the NS direction, i.e. the falling direction of the obelisk, should have been higher than $0.27 \mathrm{~g}$.

\section{COMPARISON WITH THE RECORDED GROUND MOTION}

Figure 5a-b show the NS and EW components of the acceleration time history recorded at the Amatrice seismic station (AMT), located $75 \mathrm{~m}$ downhill and about $1 \mathrm{~km}$ away of the cemetery (see Figure 1a). The data downloaded from the ESM database (ESM working group, 2015) are plotted in the most critical time window of the shaking, i.e. from $\mathrm{t}=6 \mathrm{~s}$ to $\mathrm{t}=12 \mathrm{~s}$. 
(a)

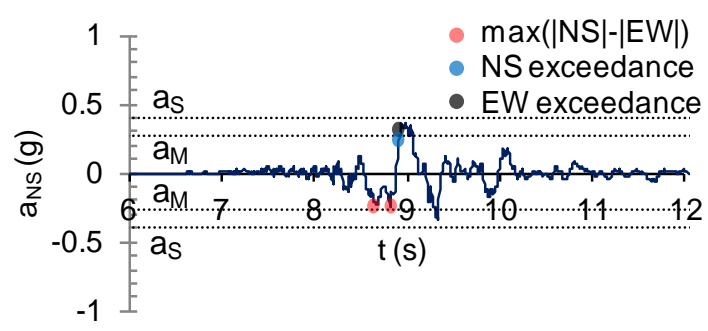

(b)

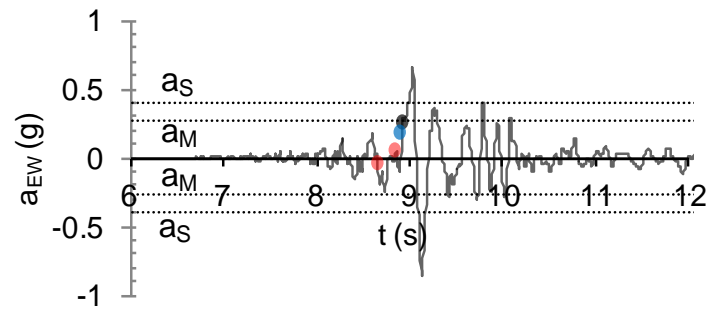

(c)

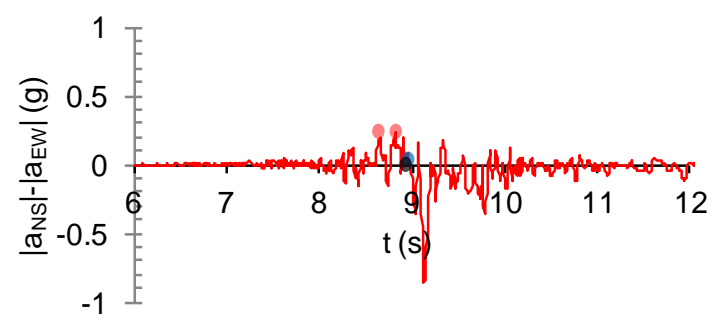

Figure 5. NS (a) and EW (b) acceleration time histories recorded in Amatrice station (AMT) and difference (c) between the absolute values of the two horizontal components.

The two limit accelerations of the obelisk, $\mathrm{a}_{\mathrm{M}}$ and as, are exceeded by several peak values of the EW component (Figure 5b), with the first of them occurring around $t=9 \mathrm{~s}$. At almost the same time, the NS component trespasses the limit overturning acceleration, i.e. $\mathrm{a}_{\mathrm{M}}=0.27 \mathrm{~g}$, having approached this threshold already two times before (Figure 5a). Since the obelisk fell down along the NS direction, its collapse likely occurred when the NS acceleration component was higher than $\mathrm{a}_{\mathrm{M}}$, and before the EW acceleration component exceeded the same threshold value. The overturning mechanism might have therefore occurred in the time interval between 8.5 and $9 \mathrm{~s}$, i.e. when the difference between the absolute values of the NS and EW components (shown in Figure 5c) is mostly positive.

Table 4 summarizes the acceleration values corresponding to the instants of the maximum difference between the two horizontal amplitudes (red dots in Figure 5) and when the NS (blue dot) and EW (black dot) components achieve the $a_{M}$ threshold for the first time.

The NS component overcomes significantly the contemporary EW value at $t=8.66 \mathrm{~s}$ and $\mathrm{t}=8.82 \mathrm{~s}$. In addition, at the same instants, the NS acceleration amplitude are $0.22 \mathrm{~g}$ and $0.24 \mathrm{~g}$, respectively, i.e. very close to $\mathrm{a}_{\mathrm{M}}$ $(0.27 \mathrm{~g})$.

The overturning critical acceleration is attained almost simultaneously in both directions, with the NS component reaching the threshold $0.01 \mathrm{~s}$ before the EW one.

Table 4. Acceleration values corresponding to the instants of the maximum difference between the two horizontal components and to the attainment of the overturning threshold in both directions.

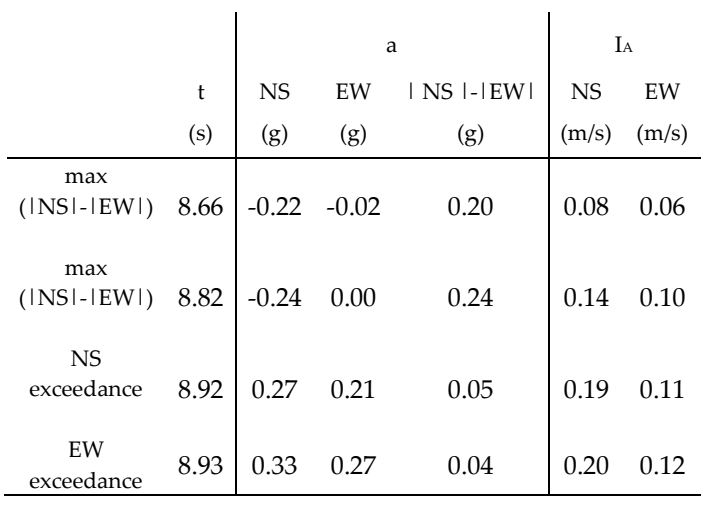


Figure 6 shows the evolution of the Arias Intensity with time, while Table 4 reports the accumulated values at the four critical instants discussed above. Although the final value of $\mathrm{I}_{\mathrm{A}}$ along EW results more than twice that relevant to the NS direction, the detail in Figure 6 reveals that, before $t=9 s$, more energy is accumulated along NS than in the EW direction. The position of the dots in the same plot and the relevant values of $\mathrm{I}_{\mathrm{A}}$ in Table 4 confirm that the temporary predominance of the NS component on that along EW direction is coherent with the direction of the failure.

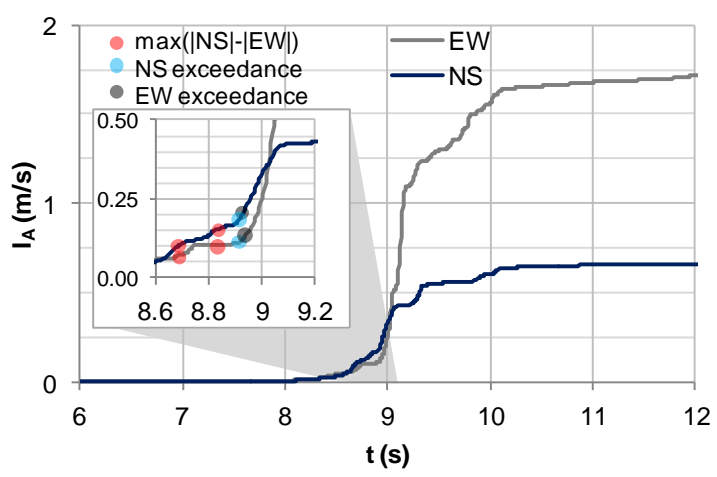

Figure 6. Arias Intensity of the NS and EW components, recorded in Amatrice.

A predominance of the NS component with respect to the EW has also been shown by the displacement inferred from the high-rate GPS data by the INGV GPS analysis group (2016), with the NS peak-to-peak value $(\approx 15$ $\mathrm{cm})$ resulting twice that corresponding to the EW direction.

Moreover, the above interpretation of the acceleration recording could not account for site effects due to the different locations of the AMT station, placed on the Laga Flysch formation representing the seismic bedrock, and the cemetery, lying on alluvial deposits constituting the hill of Amatrice (Regione Lazio, 2016), close to the steep slope bordering the northern ridge.

Thus, stratigraphic and topographic amplifications of the recorded ground motion likely occurred at the cemetery during the earthquake. Considering that the morphology of the Amatrice hill is elongated along the EW direction, the topographic amplification might have affected more significantly the NS component with respect to the EW shaking. In such hypothesis, the shaking energy associated with the NS component in the cemetery area might have been even more significant than that relevant to the EW direction. It is expected that seismic response analyses, which will be soon carried out for the seismic microzonation of the area, will corroborate such assumption.

\section{CONCLUSION AND FUTURE DEVELOPMENTS}

The paper illustrated two simple analytical approaches to interpret the observed failure of a funerary obelisk in the cemetery of Amatrice, due to the first strong motion event of the Central Italy seismic sequence. A lower bound for the peak ground acceleration occurred at the site was estimated by backanalyzing different possible failure mechanisms of the object (sliding and toppling) with reference to global limit equilibrium and yield as well as plastic local failure. The estimated peak acceleration in the NS direction may be representative of the severity of the ground motion occurred in this urban area, located far enough from the available seismic station (AMT) and in quite different site conditions. An assessment of such esti- 
mation is expected from seismic response analyses of the Amatrice ridge.

\section{REFERENCES}

Athanasopoulos G.A. (1995). Discussion of "1988 Armenia Earthquake II: Damage Statistics Versus Geologic and Soil Profiles", by M.K. Yegian, V.G. Ghahraman and G. Gazetas, Journal of Geotechnical Engineering, ASCE, 121 (4), 395-398.

EN 998:2 (2003). Specification for mortar for masonry. Part 2 Masonry mortar.

EN 1996-1-1 (2006). Eurocode 6: Design of masonry structures - Part 1-1: General rules for reinforced and unreinforced masonry structures.

ESM working group (2015). Engineering Strong-Motion database, version 1.0, DOI: 10.13127/ESM.

Galli P., Peronace E. Tertulliani A. (2016). Rapporto sugli effetti macrosismici del terremoto del 24 Agosto 2016 di Amatrice in scala MCS.

Regione Lazio (2016). Seismic Microzonation of Amatrice Municipality. Attuazione art. 11 legge n.77/2009. Draft to be approved by the Civil Protection Dept. sensu OPCM 4007/ 2012 (in Italian).

Zimmaro P. and Stewart J.P., (2016). Engineering reconnaissance following the 2016 M6.0 Central Earthquake, Ver 2. doi:10.18118/G61S3Z,http://www.geerasso ciation.org/.

INGV GPS analysis group (2016). Preliminary HRGPS results for the Amatrice earthquake. Zenodo, http://doi.org/10.5281/ze

nodo.61699.

Lanzo G., Di Capua G., Kayen R.E., Kieffer D.S., Button E., Biscontin G., Scasserra G., Tommasi P., Pagliaroli A., Silvestri F.,
d'Onofrio A., Violante C., Simonelli A.L., Puglia R., Mylonakis G., Athanasopoulos G., Vlahakis V., Stewart J.P. (2009). Seismologi$\mathrm{cal}$ and geotechnical aspects of the $\mathrm{Mw}=6.3$ l'Aquila earthquake in central Italy on 6 April 2009. International Journal of Geoengineering Case histories, http:// casehistories.geoengineer.org,1(4):206 -339 .

Maiorano R.M.S., Adinolfi M., Aversa S. (2015). Rocking of slender blocks under seismic excitation. Rivista Italiana di Geotecnica, 2/2015.

Newmark N.M. (1965) Effects of earthquakes on dams and embankments. Géotechnique 15(2):139-160,DOI 0.1680/geot.1965.15.2.139.

Yegian M.K., Ghahraman V., Gazetas G. (1994). 1988 Armenia earthquake II: Damage Statistics Versus Geologic and Soil Profiles, Journal of Geotechnical Engineering, ASCE, 120 (1), 21-45. 